\title{
MULTILITERATION PEDAGOGIC MODEL BASED ON HIGHER ORDER THINKING SKILL (HOTS) AS EFFORTS TO FACE THE 21st CENTURY EDUCATION IN EDUCATION FROM KI HADJAR DEWANTARA
}

\author{
Sigit Vebrianto Susilo, Ari Yanto
}

Universitas Majalengka

sigit.vebrianto@gmail.com

\section{Article History}

accepted 30/09/2018

approved 12/10/2018

published 30/10/2018

\section{Keywords}

creative thinking, learning,

thematic

\begin{abstract}
The character of Indonesian education today in practice is a rape of the inner and inner life of children. As a result, children are damaged in character because they always live under duress / pressure. According to Ki Hadjar, such a way of educating will not be able to shape a person until he has a "personality". In line with this view, education in Indonesia should provide a sense of security, fun, calm, and provide a sense of happiness so that students are without coercion and naturally eat knowledge to the full. On the other hand, the macro life demands of the 21st century and the adoption of a new curriculum in Indonesia in micro terms requires education to produce graduates who have the competence of life in the 21 st century. Entering the 21 st century technological advances have entered various facets of life, not least in the field of education. The characteristics of the 21st century are characterized by the growing development of the world in the field of science and technology, so that in this view in various aspects experience a shift in cultural values in daily life. Therefore, it is necessary to be the next generation of the nation to dissect the essence of the concept of education according to Ki Hajar Dewantara in the view of multiliteration education. Multiliteration education that gives students freedom to think, create, and argue is in line with the concept of pancadarma proposed by Ki Hajar Dewantara. Furthermore, multiliteration education has the characteristics of multi-concept, multi-cultural, multi-learning style, and multimulti-modal giving a concept of education that gives the impression and directs the values of Pancasila. The 21st century provides an illustration that education is increasingly important to ensure students have the skills to learn and innovate, use skills technology and information media, and can work, and survive with use life skills. In line with the explanation above, by reflecting back on the educational value of Ki Hajar Dewantara in the perspective of multiliteration education is a tangible manifestation of welcoming Indonesian education so that Indonesia will be able to realize its goal of creating a golden generation of 2045.
\end{abstract}

Social, Humanities, and Education Studies (SHEs): Conference Series https://jurnal.uns.ac.id/shes
p-ISSN 2620-9284

e-ISSN 2620-9292 


\section{PENDAHULUAN}

Pendidikan Indonesia dewasa ini diguncang dengan berbagai permasalahan komplek berakar yang mengakibatkan hilangnya jati diri dari pendidikan dalam konteks ke Indonesiaan. Sejumlah fenomena yang terjadi belakangan ini memberikan tamparan keras bagi pelaku pendidikan yang memberikan gambaran boboroknya nilai-nilai dan esensi dari pendidikan itu sendiri. Tujuan pendidikan nasional yang tertera UUD 1945 yakni setiap warganegara berhak memperoleh pendidikan yang paripurna secara manusiawi seakan kehilangan arah orientasi dan tujuannya. Hal ini sejalan dengan pemikiran H.A.R Tilaar dkk. (2011: 13) yakni "pendidikan sebagai proses adalah berarti bahwa pendidikan merupakan suatu peristiwa memanusia. Bertemali dengan pendapat Tilaar dkk di atas, pendidikan semestinya mampu memberikan tempat yang nyaman terhadap seluruh pelaku didalamnya sehingga pendidikan akan mampu melahirkan generasi yang bermutu dan bermartabat.

Seiring dengan perkembangan zaman, pendidikan muncul dalam berbagai bentuk dan paham. Dilihat dari sejarahnya, Pendidikan Indonesia dapat dibagi secara urutan waktu kurang lebih sebagai berikut: (a) jaman pra-kolonial: masa prasejarah dan masa sejarah, (b) jaman kolonial ketika sistem pendidikan 'modern' dari Eropa diperkenalkan, dan (c) jaman kemerdekaan RI yang berlangsung hingga sekarang. Masing-masing jaman memiliki corak dan bentuk tersendiri (Rohman \& Wibowo: 2016). Memasuki abad ke-21 sekarang ini, Pendidikan Indonesia dihadapkan dengan sejumlah tantangan dan peluang, yang tentunya berbeda dengan jaman-jaman sebelumnya. Guna mengantisipasi dan menyesuaikan diri dengan berbagai tuntutan dan dinamika perubahan yang sedang dan akan terus berlangsung di Abad ke-21 ini. Sementara H.A.R Tilaar (2012a: 79) mengungkapkan bahwa masyarakat dan bangasa Indonesia adalah bagian dari kehidupan global dan oleh sebab itu tidak terlepas dari gelombang perubahan sosial yang terjadi, yaitu proses demokrasi yang di dalamnya termasuk hak asasi manusia, perkembangan yang sangat pesat dari ilmu pengetahuan dan tknologi khususnya teknologi informasi, dan proses globalisasi yang mengena seluruh aspek kehidupan manusia Indonesia.

Praktik pembelajaran berbagai mata pelajaran di Indonesia hendaknya mempunyai relevansi dengan konteks kehidupan sehari-hari. Memasuki era digital hari ini ini banyak merubah hal-hal yang sifatnya biasa digunakan berganti menjadi suatu yang tidak biasa. Kaitanya dalam hal ini adalah penggunaan berbagai alat dan atau bahan yang digunakan oleh para guru dalam pembelajaran. Konsep multimodal dalam pendidikan yang mengacu pada banyaknya jenis bahan yang dapat digunakan dalam pembelajaran literasi berimplikasi pada muculnya konsep multiliterasi. Konsep ini merupakan wujud kesadaran terhadap beragamnya cara manusia untuk berkomunikasi dan melakukan aktivitas baca dan tulis maupun jenis bahan atau media untuk kegiatan baca dan tulis. Hal itu berimplikasi pada luasnya analisis kritis yang harus dilakukan untuk menginterpretasi teks (Sari, Suryaman, Lestyarini: 2013). Sejalan dengan itu, Era digital dengan berbagai produk layanannya menjadi jalan yang efektif bagi perubahan cara berkomunikasi dengan seluruh masyarakat di seluruh penjuru dunia (Borsheim, Merrit, dan Reed, 2008; Williams, 2008; Graham, Benson, Fink,2010).

Sejalan dengan fenomena melanda dunia pendidikan Indonesia yang banyak dihiasi dengan berbagai kekerasan yang berdampak negatif bagi kondisi psikologis anak bangsa. Karakter yang akan diperkuat diantaranya adalah religius, nasionalis, mandiri, gotong royong, dan integritas. Berikutnya adalah mengintegrasikan literasi. $\mathrm{Hal}$ ini sejalan dengan pernyataan Morocco, et all (2008) bahwa keterampilan abad ke21 mengembangkan kompetensi diantaranya adalah pemahaman konsep, berpikir kritis, kolaboratif dan komunikatif, serta keterampilan berpikir kritis. Selanjutnya Morocco, et all (2008) juga memberikan penjelasan kembali bahwa kompetensi yang seyogianya dikuasai siswa dalam mengarungi abad 21 adalah kemampuan membaca, 
menulis, bericara, dan menguasai berbagai macam media dan teknologi. Selanjutnya perubahan pada kurikulum 2013 ini adalah menintegrasikan HOTS (Higher Order Thinking Skill). Bertemali dengan penjelasan di atas, maka diperlukan suatu sistem pembelajaran yang baik dan dikolaborasikan dengan penggunaan media pembelajaran yang menarik agar pembelajaran berjalan bermakna, bermutu, dan bermartabat.

\section{A. Pendidikan Abad Ke-21}

Sejalan dengan perubahan dunia, pendidikan hari ini dihadapkan dengan pesatnya perkembangan dan kemajuan teknologi. Generasi manusia hari ini yang disebut generasi milenial menunjukan perbedaan signifikan dibandingkan generasigenerasi sebelumnya. Bertemali dengan pernyataan tersebut, hari ini pendidikan dihadapkan oleh sebuah tantangan derasnya era globalisasi. Oleh sebab itu, pendidikan seyogianya menjadi penopang bagi peningkatan sumber daya manusia yang dapat dilakukan sebagai upaya dalam membangun sebuah peradaban baru dalam dinamika kehidupan yang semakin maju (Herlambang, 2018: 107).

Abad 21 juga ditandai dengan banyaknya (1) informasi yang tersedia dimana saja dan dapat diakses kapan saja; (2) komputasi yang semakin cepat; (3) otomasi yang menggantikan pekerjaan-pekerjaan rutin; dan (4) komunikasi yang dapat dilakukan dari mana saja dan kemana saja (Litbang Kemdikbud, 2013). Bertemali dengan pernyataan di atas, pendidikan abad ke-21 sangat erat kaitannya dengan kemajuan teknologi. Hampir disetiap lini kehidupan manusia hari ini tidak terlepas dari penggunaan teknologi. Sebagai contoh adalah manusia hari ini dari tingkatan anakanak hingga dewasa sangat bergantung terhadap smartphone. Berkenaan dengan ini Trilling and Fadel (2009:65) menjelaskan bahwa keterampilan ini menghendaki siswa di masa yang akan datang melek informasi, melek media, dan melek TIK.

Selanjutnya, dalam menyongsong pendidikan abad ke-21, pendidikan harus mampu meningkatkan mutu manusia yang memiliki daya kritis, kreatif, futuristik, dan berkarakter agar mamiliki kemampuan adaptif untuk dapat menjalani kehidupan dalam persoalan global (Herlambang: 2018). Menyikapi perkembangan pendidikan pada abad ke-21, setidaknya ada tiga konsep dalam pendidikan abad ke-21 adalah $21^{\text {st }}$ Century Skills (Trilling dan Fadel, 2009), scientific approach (Dyer, et al., 2009) dan authentic assesment (Wiggins dan McTighe, 2011). Bertemali dengan pendapat di atas, berikut adalah pelangi pendidikan abad ke-21 yang berorientasi terhadap pencapaian keberhasilan siswa dalam belajar (Wijaya, Sudjimat, dan Nyoto: 2016):

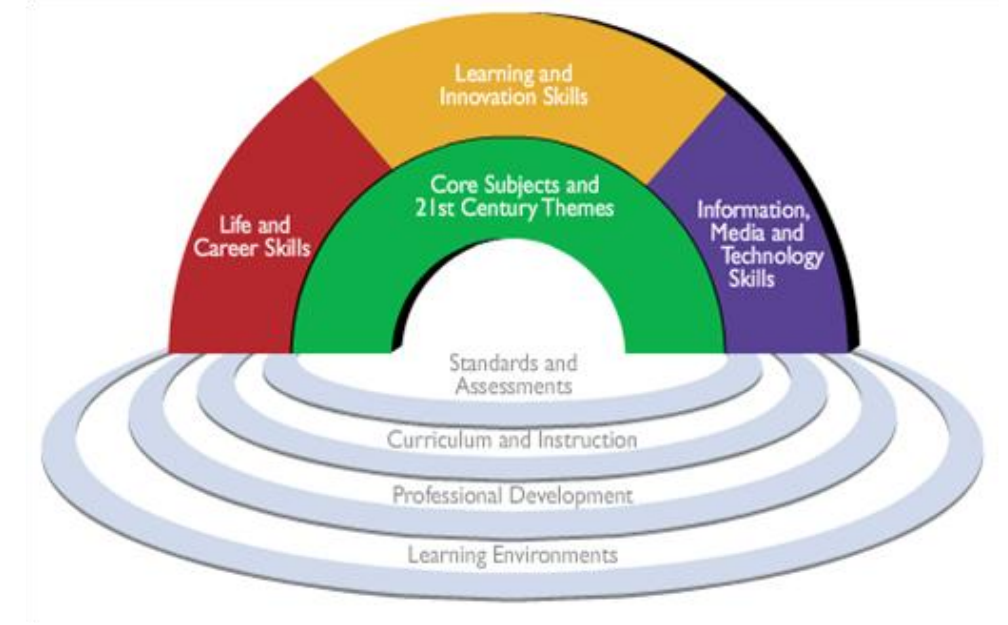

Gambar 1: Pelangi Keterampilan-Pengetahuan Abad 21 diadaptasi oleh P21 
Sejalan dengan gambar 1 di atas, terdapat beberapa keterampilan abad ke-21 yang harus dimiliki oleh setiap individu. Keterampilan tersebut adalah (1) life and career skills, (2) learning and innovation skills, dan (3) Information media and technology skills. Keterampilan tersebut adalah sebuah skema yang disebut dengan pelangi keterampilan pengetahuan abad $21 / 21^{\text {st }}$ century knowledge-skills rainbow (Trilling dan Fadel, 2009). Pendidikan pada abad 21 seyogianya dapat membentuk insan manusia menjadi manusia yang kritis dalam intelektual, kreatif dalam pemikiran, etis dalam pergaulan, dan berkarakter dalam berkehidupan (Abidin: 2015). Artinya bahwa pendidikan pada era abad ke-21 memacu manusia sebagai aktor utama dalam kehidupan di dunia untuk capakat dalam berbagai bidang. Generasi muda masa depan harus mampu tidak lagi bekerja dengan otot, namun harus mampu dengan otak, mengubah paradigma bahwa bekerja tidak hanya cukup mempunyai satu kecakapan, namun multikecakapan/ multidimensional. Atas dasar ini pendidikan segianya mampu menjadi garda terdepan dalam membina dan membentuk insan muda Indonesia mempunyai kemampuan dan kecakapan multidimensional.

\section{B. Pembelajaran Berbasis Higher Order Thinking Skills (HOTS)}

King, Goodson, \& Rohani (2010: 1) menjelaskan bahwa HOTS melibatkan beragam penerapan proses berpikir dalam situasi-situasi kompleks dan terdiri dari banyak variabel, yaitu termasuk berpikir kritis, logis, reflektif, metakognitif, dan berpikir kreatif. Selanjutnya, Brookhart (2010: 3-8) memaparkan jenis HOTS didasarkan pada tujuan pembelajaran di kelas, yaitu terdiri dari tiga kategori: HOTS sebagai transfer, HOTS sebagai critical thinking, dan HOTS sebagai problem solving. HOTS sebagai transfer didefinisikan sebagai keterampilan untuk mengaplikasikan pengetahuan dan keterampilan yang sudah dikembangkan dalam pembelajaran pada konteks yang baru. Baru di sini diartikan sebagai sesuatu yang belum diajarkan sebelumnya. HOTS sebagai transfer mencakup analysing, evaluating, dan creating (Brookhart, 2010: 62). Kemampuan berpikir peserta didik yang masih rendah perlu ditingkatkan menuju kemampuan berpikir tingkat tinggi dengan cara meningkatkan kemampuan berpikir peserta didik sampai pada kemampuan menganalisis, mengevaluasi, dan mencipta berdasarkan Taksonomi Bloom terevisi. Peningkatan kemampuan berpikir tingkat tinggi dapat dilakukan dengan menerapkan model pembelajaran aktif yang berpusat pada peserta didik dan didasarkan pada konstruktivisme (Limbach \& Waugh, 2010; Yilmaz, 2008).

Chatib (2012) kemampuan berpikir tingkat tinggi dapat membantu peserta didik untuk mencapai hasil akhir yang berkualitas dan membantu peserta didik untuk memahami suatu informasi. Oleh sebab itu, dalam pengemasan sistem pembelajaran harus senantiasa diorientasikan terhadap bagaimana mengembangkan keterampilan berpikir tingkat tinggi. Hal ini penting untuk diperhatikan karena dalam pembelajaran harus menggunakan model, metode, strategi, dan pendekatan yang sesuai kebutuhan dan beroientasi terhadap pengembangan keterampilan abad ke-21. Hal ini senada dengan yang dipaparkan oleh Kim (2005) bahwa "cultivating the student's ability to think at a higher level has been an important theme for redesigning and reforming learning systems". Senada dengan pendapat Kim (2005), Shukla (2016) juga mengemukakan "role of teaching strategies plays vital role in such inculcation where students can analyze, interpret, reason out, synthesize, evaluate and create. Teaching higher order thinking skills required time and persistent effort of the instructor which may be contextually strengthen and conceptually analyzed".

Untuk mencapai pembelajaran yang berorientasi terhadap pengembangan Higher Order Thinking Skils (HOTS). Peran guru menjadi faktor utama dalam pengemasan sistem pembelajaran. Hal ini sejalan dengan Singh et al (2018) "the teacher's knowledge of using HOTS in the class will influence the thinking skills. The teachers will use their knowledge of the thinking skills and teach this knowledge to the 
students. The accomplishment of the students depends fully on the teachers' knowledge as the teachers facilitate the students' thinking with their knowledge of teaching thinking". Guru dalam kelas memiliki peran penting dalam mengatur dan memotivasi siswa untuk berpikir tingkat tinggi. Beberapa motivasi yang dapat dilakukan guru di kelas (Conklin \& Manfro, 2010: 18): (1) membuka dan mengakhiri pelajaran dengan pertanyaan-pertanyaan yang mengarah pada keterampilan berpikir tingkat tinggi, (2) menempatkan aktivitas brainstorming pada pertengahan pelajaran untuk mendorong siswa menemukan ide dan berpikir kreatif, (3) memberikan tugas berbasis open ended sebagai pekerjaan rumah untuk mengetahui kreativitas dan pemahaman mereka terhadap pelajaran yang sudah dipelajari.

Pengemasan dan penerapan pembelajaran yang berorientasi terhadap pengembangan keterampilan berpikir tingkat tinggi tidak hanya siswa mampu menguasai materi ajar saja. Lebih dari itu, siswa diharapkan mampu mengembangkan serta mangimplementasikan dalam kehidupan sehari-hari. Selain itu, pembelajaran juga tidak sampai berhenti dalam takaran siswa sudah mampu dan mencapai batas kriteria pembelajaran saja. Namun demikian, harus benar-benar dipastikan bahwa pembelajaran yang diterapkan sampai pada tahapan siswa memiliki keterampilan yang mumpuni. Sebagai contoh dalam pembelajaran membaca. Siswa tidak hanya diajarkan bagaimana menguasai materi dari sisi konsep dan konten semata, lebih dari itu, siswa harus diarahkan untuk memiliki keterampilan membaca cepat, tepat, dan komprehensif. "It is a need of 21st century where student learn more than reading, writing or numerical ability and responsiveness, they are rather required to possess Higher Order Thinking skills such as critical literacy, critical numeracy and crosscultural competencies" (Forester, 2004).

Husamah, Fatmawati, \& Setyawan (2018) mengemukakan keterampilan yang menggambarkan siswa memiliki kemampuan berpikir tingkat tinggi yakni "six skills are considered to be achieved by students: 1) the ability to judge a source credibility; 2) identify assumptions, generalizations and biases; 3) identify connotation in language use; 4) understand the purpose of a written or spoken". Sejalan dengan Husamah, Fatmawati, \& Setyawan (2018), Peran penting keterampilan berpikir tingkat tinggi dalam pembelajaran matematika terletak pada proses pembelajaran. Siswa akan terbiasa berpikir kritis dan kreatif baik dalam pengambilan keputusan dan pemecahan masalah yang berkaitan dengan menganalisis, mengevaluasi dan mencipta (Anderson \& Krathwohl, 2001: 79). Dengan demikian, "students with HOTS are able to learn, improve their performance and reduce their weaknesses" (Yee, Othman, Yunos, Tee, Hasan, and Mohammad, 2011).

Berapa hasil penelitian berkenaan dengan Higher Order Thinkg Skills (HOTS) telah banyak diteliti oleh para peneliti. Diantaranya adalah oleh Saido, et al (2015) memnyatakan "Given the importance of cognitive skills for academic success, understanding the process of HOT skills as well as their assessment among students represents a central goal in science education". Selanjutnya Genç (2016) memaparkan hasil penelitianya bahwa "the study concludes that students have demonstrated reflective thinking skills in the aspects of questioning, reasoning, and evaluation during the activity". Berikutnya penelitian yang dilaksanakan oleh Pretorius, Greg P. Mourik, and Barratt (2017) menunjukan bahwa ": This study demonstrates that flexibility in assessment allows students to take a proactive role in their learning. When combined with activities designed to develop critical thinking, this assessment strategy can be effective in developing higher order thinking skills". Selanjutnya Benidiktus Tanujaya , Mumu \& Margono (2017) memnyimpulkan hasil penelitianya "One of the most important things that can be done to improve students' HOTS is by revising textbooks used in mathematics learning in primary and secondary schools. 
The mathematics textbooks used in Indonesia should promote students' critical and creative thinking".

\section{Merefleksi Nilai-Nilai Pendidikan Ki Hadjar Dewantara}

Sosok Ki Hajar Dewantara tidak bisa kita lepaskan dari perjalanan panjang pendidikan Indonesia. Ki Hajar Dewantara merupakan pioner dan pelopor terbentuknya sistem pendidikan di Indonesia. Keberadaannya dalam menentang penjajahan Belanda adalah dengan mendirikan Perguruan Taman Siswa. Dengan mendirikan perguruan tersebut ia bercita-cita agar bangsa Indonesia merdeka lahir batin. Pemikirannya sangat relevan sebagai sebuah terobosan dalam membangun pendidikan saat ini yang dalam keadaan kritis.

Ki Hajar Dewantara terkenal juga sebagai pejuang dan budayawan. Selanjutnya dalam konteks pendidikan, Ki Hajar Dewantara mengemukakan Panca Dharma. Panca Dharma secara umum berarti "lima asas". Lima asas pemikiran yang terhimpun dalam konsepsi tersebut adalah: asas kodrat alam, asas kemerdekaan, asas kebudayaan, asas kebangsaan, dan asas kemanusiaan (Solehan: 2010). Pancadarma memberikan sebuah gambaran dengan sendirinya mendorongkan asas aliran, haluan, anjuran, tekat, niat, dan kemauan supaya kita bisa berbuat segala apa yang berdasarkan lima dasar itu. Tentang urutan-urutan lima dasar tersebut, menurutnya tidak harus memakai urutan yang pasti atau tertentu. Sebaiknya hal ini diseseuaikan dengan caranya kita menggambarkan dasar-dasar dan asa-asas itu, misalnya sebagai berikut: berilah (kemerdekaan) dan kebebasan kepada anak-anak kita; bukan kemerdekaan yang leluasa. Namun yang terbatas oleh tuntutan-tuntutan (kodrat alam) yang hak atau yang nyata, dan menuju ke arah (kebudayaan), yakni keluhuran dan kehalusan hidup dan penghidupan diri dan masyarakat, maka perlulah dipakainya dasar (kebangsaan), akan tetapi jangan sekali-kali dasar ini melanggar atau bertentangan dengan dasar yang lebih luas, yaiuty dasar (kemanusiaan).

Semboyannya yang terkenal ialah tut wuri handayani (di belakang memberi dorongan), ing madya mangun karsa (di tengah menciptakan peluang untuk berprakarsa), ing ngarsa sung tulada (di depan memberi teladan). Bagian depan dari semboyannya, tut wuri handayani, menjadi slogan Departemen Pendidikan Nasional (Dewantara 1977: 215). Slogan yang diciptakan oleh Ki Hajar Dewantara ini mempunyai makna yang sangat mendalam bagi pendidikan. Secara harfiah Tut Wuri berarti mengikuti dari belakang, Handayani mengandung arti memberi semangat motivasi dan moral. Secara lengkap slogan tersebut berarti di depan memberikan contoh, di tengah memberi semangat, di belakang memberi dorongan. Jika diinterpretasikan slogan ini mengandung makna bahwa siorang guru harus memberikan dorongan, contoh dan menciptakan kreativitas terhadap anak didiknya.

Dari sudut pandang isinya, pendidikan yang digagas oleh Ki Hadjar Dewantara memiliki kriteria-kriteria yang secara eksplisit mengandung enam unsur, yaitu: 1) pendidikan kebebasan (merdeka), 2) pendidikan kemanusiaan (humanisme), 3) pendidikan spiritual (kodrat alam), 4) pendidikan budi pekerti, 5) pendidikan sosial (kekeluargaan) dan 6) pendidikan kepemimpinan (Tut Wuri Handayani) (Muthoifin: 2015). Bahkan, berbagai aspek yang terkait dengan pendidikan seperti visi, misi, tujuan, kurikulum, metode, dan tahapan pendidikan lainnya harus dirumuskan berdasarkan kemauan bangsa Indonesia yang berasal dari berbagai suku, etnis, dan budaya yang beraneka ragam. Sehingga gagasan dan pemikiran dari Ki Hadjar inilah yang kemudian menjadi acuan penyelenggaraan pendidikan nasional hingga sekarang ini.

Apalagi gagasan dan pemikiran pendidikan Ki Hadjar yang sudah ditulis dalam berbagai karangannya, mendapat sambutan hangat dari Presiden Republik Indonesia pertama Ir. Soekarno. Sebagaimana gagasan tentang prinsip pendidikan yang berbunyi Ing ngarso sung tulodo, Ing madya mangun karso, Tut wuri handayani adalah 
berasal dari buah pemikirannya. Begitu juga konsep Sistem Among (sistem pengajaran) dan Kodrat Alam (kehendak alam) juga merupakan buah gagasan dari pemikirannya. Sistem Among adalah suatu sistem pendidikan yang berjiwa kekeluargaan yang bersendikan kodrat alam dan kemerdekaan. Sistem Among ini berdasarkan cara berlakunya disebut sistem Tut wuri Handayani. Dalam sistem ini orientasi pendidikan adalah pada anak didik, yang dalam terminologi baru disebut student centered. Sedangkan Kodrat alam adalah perwujudan dari kekuasaan Tuhan yang mengandung arti, bahwa pada hakekatnya manusia sebagi mahluk Tuhan adalah satu dengan alam lain. Menurut Ki Hajar, pada hakekatnya manusia sebagai makhluk Tuhan adalah satu dengan kodrat alam ini. Artinya, manusia merupakan satu kesatuan tak terpisahkan dengan jagad raya ciptaan Tuhan. la hanya berhasil dalam hidupnya selama ia mengikuti dan mematuhi kodrat alam yang memiliki banyak hal positif bagi manusia, termasuk penyediaan fasilitas dalam mencapai kemudahan dan keberhasilan hidup manusia (Dewantara: 1981).

Konsep pendidikan Ki Hadjar Dewantara menegaskan bahwa pendidik atau guru merupakan bukan satu-satunya pemegang peranan danlam pembelajaran. Peran guru dalam hal ini adalah lebih kepada fasilitator, pengarah, pembimbing, dan pemberi motivasi. Dalam proses pembelajaran, sikap yang ditunjukan guru menekankan pada sifat egaliter atau kesetaraan. Kesetaraan disini adalah tidak adanya batasan secara posisi atau kedudukan atau tidak ada perbedaan yang menonjol antara guru dan siswa. Sifat egaliter ini akan memberikan rasa nyaman kepada siswa sehingga peroses pembelajaran akan berlangsung dengan efektif dan efisien. Terciptanya suasana kasih sayang dan persahabatan yang erat antara guru dan siswa akan menciptakan pendidikan dan pembelajaran secara harmonis, bermutu, dan bermartabat. Dengan kata lain, pendidikan tidak hanya diisi oleh proses transfer knowladge saja, akan tetapi pendidikan juga harus diisi dengan proses pengembangan keterampilan serta diimbangi dengan pembentukan karakter yang baik.

\section{Model Pedagogik Multiliterasi}

Pedagogik adalah ilmu yang menjadi dasar atau landasan dalam melaksanakan pendidikan. Pedagogik merupakan sebuah pijakan awal dari sebuah dinamika kehidupan pendidikan yang berjalan dinamis. Dariyo (2013: 2) mengatakan bahwa pedagogy diartikan sebagai disiplin ilmu yang mempelajari proses, tujuan dan manfaat kegiatan pendidikan bagi pengembang segenap potensi individu maupun kelompok dari masa bayi sampai dewasa, agar menjadi warganegara yang bertanggungjawab di masyarakat. Selanjutnya Menurut Prof. Dr. J. Hoogveld (Belanda) (Sadulloh, dkk, 2009: 2) menyatakan bahwa pedagogic adalah ilmu yang mempelajari masalah membimbing anak kearah tujuan tertentu, yaitu supaya ia kelak mampu secara mandiri menyelesaikan tugas hidup dan kehidupannya. Sadulloh dkk. (2009) mendefinisikan pedagogik sebagai suatu teori dan kajian yang secara teliti, kritis, dan objektif mengembangkan konsep-konsepnya mengenai hakikat manusia, hakikat anak, hakikat tujuan pendidikan serta hakikat proses pendidikan.

Namun demikian, kajian pedagogik tidak hanya berkecimpung dalam pendidikan dan pembimbingan anak saja. Herlambang (2018) secara spesifik mengemukakan bahwa pedagogik adalah ilmu yang mengkaji secara kritis mengenai hakikat manusia dan pendidikan yang meliputi proses, tujuan, dan manfaat pendidikan. pedagogic adalah kompetensi yang menacakup dimensi memahami hubungan manusia dengan manusia. Adalah kompetensi guru dalam dimensi memahami ruang lingkup hidup dan kehidupan manusia secara utuh.

Pedagogic adalah kajian ilmu secara praktis yang artinya merupakan suatu kesatuan antara ilmu dan tindakan mendidik. Dalam tindakan mendidik diasumsikan adanya suatu objek dalam tindakan tersebut. Objek tindakan tersebut selanjutnya dapat disebut berupa anak, peserta didik, atau orang lain (Tilaar, 2012b: 257). 
Herlambang (2018) menjelaskan bahwa Pedagogik merupakan ilmu yang mengkaji secara kritis hakikat manusia, dan hakikat pendidikan yang meliputi proses, tujuan dan manfaat pendidikan sebagai upaya dalam mengembangkan potensi manusia dan mengantarkan manusia pada hakikat kemanusiaannya sebagai makhluk multidimensi melalui proses pendidikan, yang bertujuan untuk menumbuhkan kedewasaan dalam multiaspek untuk menjalani kehidupan.

Selanjutnya, multiliterasi dapat dijelaskan sebuah konsep pembelajaran yang mengarahkan siswa untuk dapat mengembangkan keterampilan-keterampilan multiliterasi. Konsep pembelajaran multiliterasi membimbing dan mengarahkan siswa untuk dapat memperoleh pembelajaran secara kompleks tidak hanya berorientasi terhadap penguasaan konsep dan konten. Akan tetapi, pembelajaran multiliterasi mengarahkan siswa untuk dapat belajar secara mandiri dan mengembangkan keterampilan berpikir tingkat tinggi (HOTS).

Pengembangan konsep multiliterasi dalam dunia pendidikan sebenarnya tidak pernah terlepas dari konsep pedagogik berbasis seni, multiple ways of knowing, dan multipelintelegensi bagi siswa (Abidin, 2015: 57). Sejalan dengan hal tersebut multiliterasi juga diyakini mampu mengembangkan kreafitas tingkat tinggi sebagai keterampilan penting bagi siswa. New London Group (2006) dalam Pedagogy of Multiliteracies menyatakan bahwa "selain adanya konsep conventional reading and writing, digital literacy, visual literacy dan critical literacy menjadi aspek penting dalam praktik multiliterasi di kelas". Selain pembelajaran yang berfokus pada peserta didik, pemahaman terhadap bahasa sebagai konstruksi sosial juga akan lebih dipahami dengan baik sehingga diharapkan dapat lebih meningkatkan respons siswa terhadap fenomena di sekitar (Herlambang: 2018).

Selanjutnya, Menurut Abidin (2015: 8) "multiliterasi adalah kemampuan berbahasa yang bertemali dengan konteks, budaya, dan media". Pembelajaran multiliterasi merupakan pembelajaran yang berfokus pada pengoptimalan terhadap segala aspek belajar. Dalam pembelajaran multiliterasi ini memfokuskan pada pengembangan kemampuan peserta didik bukan pada pencapaian kompetensi. Sehingga dalam hal ini peserta didik lebih dapat menghargai perbedaan setiap individu dan percaya bahwa setiap individu dilahirkan istimewa, yakni memiliki kekurangan dan kelebihan masing-masing. Dafit (2017) memandang bahwa "model multiliterasi adalah model pembelajaran yang terkait dengaan penggunaan alat dan berbagai macam sumber belajar, ilmu pengetahuan lainnya serta menempatkan kemampuan membaca seefisien mungkin untuk meningkatkan kemampuan berpikir kritis, pemahaman konseptual, kolaboratif dan komunikatif".

Pendidikan multiliterasi diyakini mampu membantu siswa dalam memahami perbedaan sosial budaya dan komunikasi. multiliterasi bertujuan menjadikan praktik literasi di sekolah sebagaimana praktik literasi yang siswa lakukan di rumah dan lingkungan informal. Dalam pandangan ini, multiliterasi juga merupakan pendekatan pembelajaran yang dikembangkan berdasarkan kesadaran dan pengakuan atas keberagaman dan kompleksitas prespektif budaya siswa dan keberagaman gaya belajar yang dimilikinya. Oleh sebab itu pendidikan multiliterasi diyakini mampu menjembatani siswa untuk dapat belajar dan berkarya pada abad ke-21.

Pedagogik multiliterasi adalah sebuah gagasan implementasi pendidikan yang berorientasi terhadap pengembangan keterampilan dalam multi perspekti dan multi dimensional. Dalam pandangannya, pedagogik multiliterasi dibangun atas dasar situasi sosial budaya yang menjadi unsur fundamental dan merupakan salah satu bentuk pendidikan berdasarkan pada pendekatan multibudaya (Herlambang: 2018). Cope dan Kalantzis (2005) berpendapat bahwa pedagogik multiliterasi menyajikan sebuah pengalaman belajar yang efektif dan efisien. Selain itu, Pedagogik Multiliterasi kritis dapat dikatakan pula sebagai model pendidikan yang didasarkan pada penggunaan media informasi dan situasi kehidupan nyata melalui pembelajaran lintas 
disiplin sebagai upaya dalam mengoptimalkan potensi siswa. The New London Group (2005) menyatakan bahwa pedagogik multiliterasi dibangun oleh empat komponen yakni situasi praktis, pembelajaran yang jelas, bingkai kritis, dan transformasi kritis (Herlambang: 2018). Lebih lanjut, Cope and Kalantzis (2005) menyatakan bahwa empat komponen tersebut satu kesatuan utuh yang saling memperkuat satu sama lain.

Konsep pedagogik multiliterasi memberikan gambaran kepada seluruh insan pendidikan bahwa pendidikan tidak hanya berorientasi terhadap penguasaan konsep dan konten secara mekanis dan metodologis semata. Namun demikian, konsep pedagogik multiliterasi memberikan paradigma bagi pendidikan Indonesia bahwa sudah saatnya bahwa sistem pendidikan yang berlaku adalah sistem pendidikan dalam konteks kelndonesiaan. Pendidikan dalam konteks pedagogik multiliterasi harus dibangun melalui konsep pendidikan sosio-kultural masyarakat Indonesia. Selanjutnya pendidikan dalam pandangan pedagogik multiliterasi adalah pendidikan yang memerdekakan gaya dan pemikiran siswa. Artinya bahwa pendidikan tidak dilaksanakan dengan egosentris dari guru bahwa pembelajaran yang dilaksanakan harus sesuai dengan kemauan dari guru. Oleh sebab itu, pendidikan harus dibangun dan berorientasi terhadap mengembangkan potensi, minat, dan bakat manusia yang dalam prosesnya melalui pengembangan keterampian beripikir tingkat tinggi (kritis, kreatif, dan metakognitif), kemampuan berkomunikasi, serta bagaimana siswa dapat memiliki kemampuan adaptif. Selain itu pendidikan juga harus berorientasi terhadap bagaimana mengembangkan manusia masa depan Indonesia yang futuristik, memiliki multi kompetensi, dan mengembangkan pendidikan berbasiskan multi budaya.

\section{SIMPULAN}

Pendidikan abad ke-21 dengan berbagai perubahan dalam setiap dimensi kehidupan manusia menuntut setiap elemen masyarakat untuk turut serta di dalamnya. Sebagai masyarakat dunia, manusia harus memiliki kemampuan adaptif sehingga setiap apapun perubahan kita mampu untuk beradaptasi dengan baik. Namun sejalan dengan perubahan dunia dengan derasnya era globalisasi yang serba digital, konsep pendidikan dalam konteks kelndonesiaan perlu dikembangkan agar jati diri bangsa tidak tergerus oleh kerasnya era globalisasi. Pendidikan dengan berbasiskan nilai-nilai luhur yang berorientasi terhadap penanaman nilai-nilai kebudayaan lokaal harus tetap dikembangkan dan dilestarikan.

\section{DAFTAR PUSTAKA}

Abidin, Y.(2015) "Pembelajaran Multiliterasi: Sebuah Jawaban atas Tantangan Pendidikan Abad Ke-21 dalam Konteks Keindonesiaan". Bandung: PT Refika Aditama.

Anderson, L.W., \& Krathwohl, D.R. (2001) "A Taxonomi For Learning, Teaching, and Assesing: A Revision of Blom's Taxonomy of Education Objectives". Addision Wesley Lonman Inc. New York

Borsheim, Carlain, Memitt, Kelly., \& Reed, Dawn. (2008) "Beyond Technology for Tecnology's Sake: Advancing Multiliteracies in The Twenty-First Century' dalam The Cleaning House November-Desember.www.proquest.umi.pgd/web.

Brookhart, S. M. (2010). How to assess higher-order thinking skills in your classroom. Alexandria, Virginia: ASCD.

Chatib, M. (2012). Orangtuanya Manusia. Bandung: Kaifa.

Conklin, W., \& Manfro, J., (2010). "Higher Order Thinking Skills To Develop 21st Century Learners. Shell Education Publising, Inc. Huntington.

Cope, B. dan Kalantzis, M. (2005). Multiliteracies: Literacy Learning and the Design of Social Futures. New York: Routledge. 
Dafit, F (2017) Keefektifan Kemampuan Menulis Kreatif Siswa SD Dengan Model Pembelajaran Multiliterasi: Jurnal GERAM (Gerakan Aktif Menulis) Volume 5, Nomor 1, Juni 2017. Pp 49-57.

Dariyo, A.(2013). Dasar-Dasar Pedagogi Modern.Jakarta: PT. Indeks.

Dewantara, Ki Hadjar. (1964). Asas-asas dan Dasar-dasar Tamansiswa,Yogyakarta: Majlis Luhur Tamaniswa.

Dewantara, Ki Hajar. (1981). Asas-Asas dan Prinsip Taman Siswa. Jakarta: Balai Pustaka.

Dewantara, Ki Hajar (1977). "Bagian Pertama: Pendidikan. Yogyakarta: Majelis Luhur Persatuan Taman Siswa.

Dyer, Jeffrey H. Gregersen, Hal B., and Christensen, Clayton M. (2009) The innovator 's DNA, Harvard Business Review, December 2009, pp. 1-10.

Forester M. (2004). Thinking skills, Research Development, vol 11 art 1 retrieved from http://www.reesracher.acer.edu.au/cgi/videocontent.cgi.

Genç, M.A. (2016) Evaluation of Gifted and Talented Students' Reflective Thinking in Visual Arts Course. Universal Journal of Educational Research 4(9) , 2016: pp. 2039-2048.

Graham, Meadow Sherril, Sheila Benson, Lisa Storm Fink. (2010). "A Springboard Rather Than a Bridge: Diving into Multimodal Literacy" dalam English Journal (High School Edition) Urbana: November, vol 200, 153.

H.A.R Tilaar dkk. (2011). Pedagogic Kritis: Perkembangan Substansi, dan Perkembanganya dl Indonesia. Jakarta: Rineka Cipta.

H.A.R.Tilaar (2012a). "Perubahan Sosial dan Pendidikan: Pengantar Pedagogik Transformatif Untuk Indonesia". Jakarta: Rineka Cipta.

H.A.R Tilaar. (2012b). Standarisasi Pendidikan Nasional: Suatu Tujuan Kritis. Jakarta: Rineka Cipta.

Herlambang, Y.T. (2018) PEDAGOGIK: Telaah Kritis IImu Pendidikan Dalam Multiperspektif. Tasikmalaya: Ksatria Siliwangi.

Husamah, Fatmawati, D., \& Setyawan, D. (2018) OIDDE Learning Model: Improving Higher Order Thinking Skills of Biology Teacher Candidates. International Journal of Instruction April 2018 Vol.11, No.2. pp. 249-264

Kemendikbud. Penyelenggaraan Pendidikan Sistem Ganda pada Sekolah Menengah Kejuruan. Jakarta: Direktorat Pendidikan Menengah Kejuruan.

Kim, Y. (2005). Cultivating reflective thinking: The effects of a reflective thinking tool on learners' learning performance and metacognitive awareness in the context of on-line learning. (Ph.D dissertation, The Pennsylvania State University). Retrieved from http://search.proquest.com/docview/305419245?accountid=28930

King, F. J., Goodson, L., \& Rohani, F. (2010). Assessment \& evaluation educational services program: Higher-order thinking skills. Washington, DC: A publication of the Educational Services Program.

Limbach, B., \& Waugh, W. (2010). Developing higher level thinking. Journal of Instructional Pedagogies, 3, 1-9.

Morocco, C.C., et al. (2008). Supported Literacy for Adolescents: Transforming Teaching and Content Learning for The Twenty-First Century. San Francisco: Jossey-Bass A Wiley Imprint.

Muthoifin. (2015). "Pemikiran Pendidikan Multikultural Ki Hadjar Dewantara". Jurnal Intizar, Vol. 21, No.2, 2015: Institut Agama Islam Surakarta Indonesia.

New London Group. (1996). "A Pedagogy of Multiliteracies: Designing Social Futures" dalam Harvard Educational Review, 66.

Pretorius, L, Greg P. van Mourik, and Barratt, C. (2017) Student Choice and HigherOrder Thinking: Using a Novel Flexible Assessment Regime Combined With Critical Thinking Activities to Encourage the Development of Higher Order 
Thinking. International Journal of Teaching and Learning in Higher Education 2017, Volume 29, Number 2. pp. 389-401.

Rohman, S., \& Wibowo, A. (2016) "Filsavat Pendidikan Masa Depan: Kajian Filsavat Pendidikan Masa Depan" Yogjakarta: Pustaka Pelajar.

Sadulloh, U. dkk.(2009). Pedagogik (Ilmu Mendidik). Bandung: Alfabeta.

Saido, G. M., Siraj, S., Nordin, A.B.B, Al_Amedy, O. S. (2015) Higher Order Thinking Skills Among Secondary School Students in Science Learning. The Malaysian Online Journal of Educational Science 2015 (Volume3 - Issue3). pp.13-20.

Shukla, D. (2016) Student's Perceived Level and Teachers' Teaching Strategies of Higher Order Thinking Skills; A Study on Higher Educational Institutions in Thailand. Journal of Education and Practice. Vol.7, No.12, 2016. pp. 211-219

Singh, C. K. S., Singh, R.K.A., Singh, T.S.M., Mostafa1, N. A., \& Mohtar, T.M.T. (2018) Developing a Higher Order Thinking Skills Module for Weak ESL Learners. Canadian Center of Science and Education. English Language Teaching; Vol. 11, No. 7 ; 2018. pp. 86-100.

Solehan (2010) Konsepsi Panca Dharma Ki Hadjar Dewantara Ditinjau Dari Sudut Pandang. TA'DIB, Vol. XV No. 01. Edisi, Juni 201. pp. 1-30.

Tanujaya, B., Mumu J., \& Margono G. (2017) The Relationship between Higher Order Thinking Skills and Academic Performance of Student in Mathematics Instruction. International Education Studies; Vol. 10, No. 11; 2017. pp. 78-85.

Vernez, G., Culbertson, S., \& Constant, L. (2014). Strategic Priorities for Improving Access to Quality Education in the Kurdistan Region-Iraq. Santa Monica, CA: RAND Corporation. Retrieved from http://www.rand.org/pubs/monographs/MG1140z2-1

Wiggins, Grant dan Jay McTighe. (2012). Pengajaran Pemahaman Melalui Desain. Jakarta: Indeks.

Wijaya, Etistika Y., Sudjimat, Dwi A, dan Amat, Nyoto (2016) Transformasi Pendidikan Abad 21 Sebagai Tuntutan Pengembangan Sumber Daya Manusia Di Era Global. rosiding Seminar Nasional Pendidikan Matematika 2016. Volume 1 Tahun 2016 - ISSN 2528-259X. pp. 263-278.

Williams, Bronwyn T. (2008). "Tomorrow will not be like today": Literacy and Identity in a World of Multiliteracies. International Reading Association. www.proquest.umi.pqd/web.

Yee, Othman, Yunos, Tee, Hasan, and Mohammad, (2011) The Level Of Marzano Higher Order Thinking Skills Among Tecknical Education Students. Internasional Journal of Social Science and Humanity,1(2), pp. 121-125

Yilmaz, K. (2008). Constructivism: Its Theoretical Underpinnings, Variations, and Implications for Classroom Instruction. Turkey: Educational Horizons. 